\title{
135. Crustal Movements as Indicated by an Elevated Shoreline near Yuzaki, Kii Peninsula, Japan.
}

\author{
By Gakurô Imamura. \\ Geographical Institute, College of Literature and Science, Tokyo.
}

(Comm. by H. YABE, M.I.A., Oct. 12, 1934.)

To measure an elevated shoreline is, as it were, to examine the results of two successive levelings carried out with an enormous interval of time between them. Quite a number of uplifted shorelines have. been studied by various Japanese geomorphologists, but all these investigations were based upon data obtained by mere map-readings, which are not always reliable. The present study is one of the first efforts to examine elevated shorelines by direct field measurements.

The area in question consists entirely of Tertiary strata of Vindobonian and Sarmatian age, which are folded and faulted by a lateral force that acted in a north-south direction. These deformed formations were then truncated by four groups of erosion surfaces, namely ;

$$
\begin{array}{rrrl} 
& & \text { Aproximate altitude. } & \multicolumn{1}{c}{\text { Origin. }} \\
\text { (I) } & \text { Surface of erosion } & 100+ & \text { subaerial (?) } \\
\text { (II) } & \text { " } & 70-90 & \text { marine } \\
\text { (III) } & \text { " } & 20-50 & \text { marine }
\end{array}
$$$$
\text { (II) " } \quad 70-90 \quad \text { marine }
$$$$
\text { (IV) " } 0 \text { marine }
$$

Surface (I) is met with only on the summit of the hills, while surfaces (II) and (III) are conspicuous by their characteristic topography as typical coastal terraces (Fig. 1). Surface (IV) is nothing but an abrasion surface in process of formation. Abrasion surfaces at the present sea level are quite common along the coast of Kii Peninsula.

Upon these terrace surfaces are found in many localities thin veneers of marine sediments and scattered marine boulders of considerable size, which besides furnishing us with proofs of the origin of these terraces, enabled me to determine the former beach line (Fig. 1). The existence, moreover, of old sea cliffs and the absence almost of fluviatile gravel beds permitted me to measure the present altitude of elevated shorelines at 52 points with fairly high accuracy, geomorphologically speaking. The results are shown in Figure 2.

It is necessary to consider the sources of the errors that might creep into these results. First of all, an error will invariably be present 


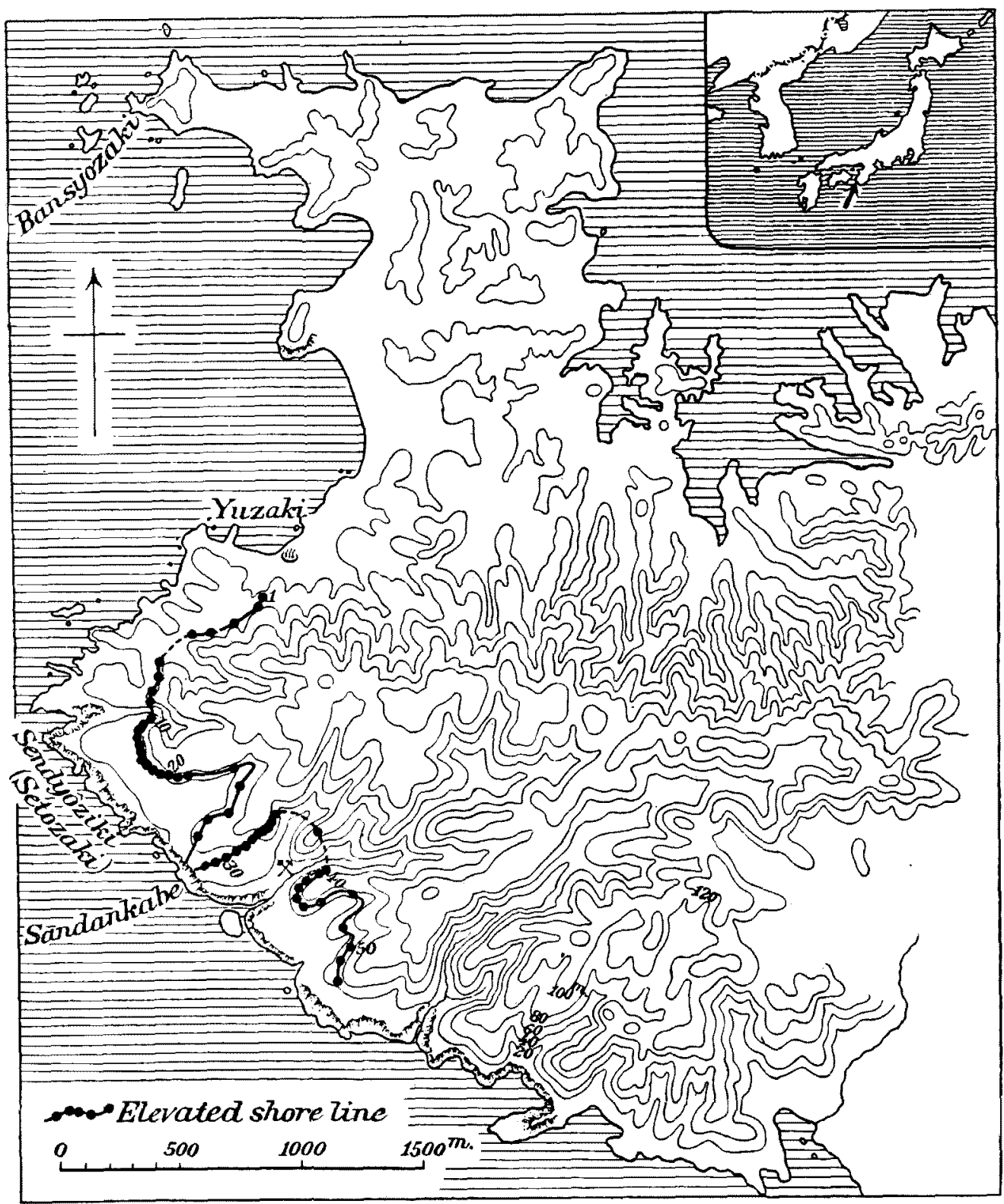

Fig. 1 .

whenever we select a point upon the supposed former beach-line, although this error may be assumed to be less than three metres. Secondly, the determination of the altitude by means of an aneroid may introduce an error not exceeding five metres. Finally, since determinations of the relative positions of the measured points were carried out with the aid of a topographical map (scale 1:50,000), an element of doubt enters, so that the presence of errors of this kind forbids discussing the gradient in too great a detail.

Everything considered, however, the results shown in Figure 2 
No. 8.] Crustal Movements as Indicated by an Elevated Shoreline near Yuzaki. 485

can not be attributed to these errors alone, as will be seen upon paying attention to the systematic arrangements of the measured shoreline shown in Figure 2. We have at least two alternative explanations for these results: (1) crustal movements, and (2) certain other causes quite unrelated to crustal deformation.

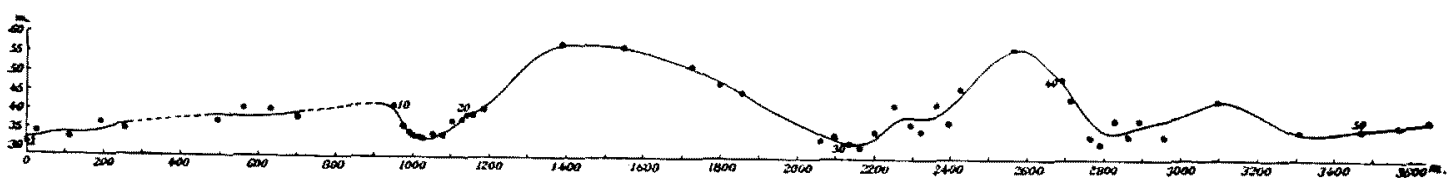

Fig. 2.

Any explanation denying a crust deformation in this region is untenable, because (1) the fluviatile accumulation is not thick enough to explain such differences of altitudes from former shorelines; (2) overwash, by itself, cannot be invoked to explain such a large amount of change; (3) talus deposits do exist, but they could lead to errors that always occur in the same sense. Moreover, they are not confined to the inner parts of former bays.

Explanation by crustal movements is much more reasonable; the mode of movements being shown in Figure 3. We have reasons for stating that we have here no tilting (note the form of the 35 metres eohypsen!), that simple doming must be rejected, and that a kind of dome-like uplift with wavy sides must be recognized. Besides this general tendency, there is a minor faulting near the abandoned mine, which was actively going on after the formation of the shoreline I have mentioned.

In conclusion, I wish to summarize the foregoing as follows: (1) The emergence of this shoreline is not the result of an eustatic change of level. (2) We must ad-

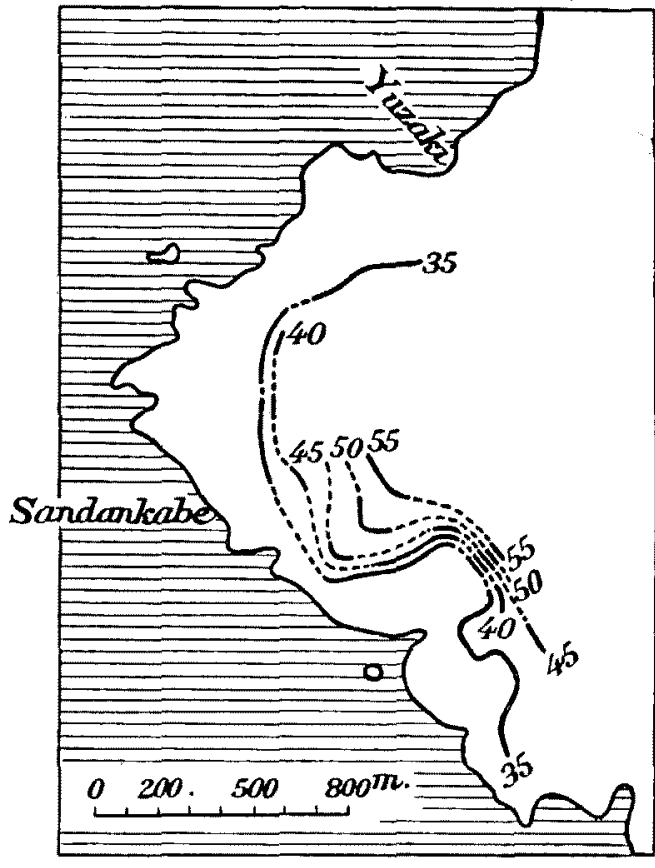

Fig. 3. mit a considerable crustal deformation that amounted to $5.4 \times 10^{-2}$ in its average gradient. (3) As is clearly seen in Figs. 1 and 2, some relation seems to exist between crustal movement and the river spacing. 